\title{
EDUCAÇÃO INCLUSIVA E O TRANSTORNO DO ESPECTRO AUTISMO
}

\author{
Ariele dos Santos Bortolozo Rodrigues* \\ Natacya M. O Caetano**
}

RESUMO: O Transtorno do Espectro Autista é um transtorno do neurodesenvolvimento que acarreta inúmeras crianças em idade escolar. A inclusão das crianças autistas no ensino regular traz, ainda hoje, muitas preocupações à escola, assim como aos pais e professores. Esse artigo tem como objetivo demostrar os desafios enfrentados para fazer a inclusão dos autistas na Educação do Ensino Regular, na qual aborda a breve história do Transtorno do Espectro Autista, suas características, a Legislação 12.764 de 2012 e o âmbito que engloba de forma resumida os desafios que possui, tendo como base a Escola Municipal Mauro Fascincani. O estudo foi realizado através de revisão teórica de artigos tem como os principais teóricos Mello, Rodrigues, Suplinos, Bereohff. Também estão inseridos nesse artigo a contribuição da intervenção pedagógica e os métodos utilizados no Brasil para aprendizagem do autista. Realizou-se ainda entrevistas, com profissionais da educação que falam sobre os obstáculos encontrados em desenvolver trabalhos pedagógicos e duas mães de crianças autistas que relatam as dificuldades encontradas ao matricular seus filhos na escola regular. Espera-se que esse artigo contribua para o conhecimento acadêmico, profissional, familiar e social, no que se refere aos avanços e possibilidades de melhorias em relação ao atendimento e tratamento das crianças com autismo no ambiente escolar.

ABSTRACT: Autistic Spectrum Disorder is a neurodevelopmental disorder that causes numerous school children. The inclusion of autistic children in mainstream education still brings many concerns to school, as well as to parents and teachers. This article aims to demonstrate the challenges faced to include autism in regular education, in which it discusses the brief history of Autism Spectrum Disorder, its characteristics, Legislation 12.764 of 2012 and the scope that briefly encompasses the challenges it has, based on the Mauro Fascincani Municipal School. The study was carried out through a theoretical review of articles whose main theorists are Mello, Rodrigues, Suplinos, Bereohff. Also included in this article are the contribution of pedagogical intervention and the methods used in Brazil for learning the autistic. Interviews were also conducted with education professionals who talk about the obstacles encountered in developing pedagogical works and two mothers of autistic children who report the difficulties encountered when enrolling their children in regular school. It is hoped that this article will contribute to academic, professional, family and social knowledge, with regard to advances and possibilities for improvements in relation to the care and treatment of children with autism in the school environment.

PALAVRAS-CHAVE: Autismo, Educação, Desafios, Inclusão.

KEY WORDS: Autism, Education, Challenges, Inclusion.

INTRODUÇÃO 
A inclusão das crianças autistas no ensino regular traz muitas preocupações à escola, pois ainda há falta de embasamento para atender esses alunos, falta de profissionais capacitados e estrutura escolar, baseados nesses fatores foi desenvolvido esse artigo, na qual foram realizadas pesquisas de campo com os profissionais da Escola Municipal Mauro Fascincani que expuseram as dificuldades encontradas para fazer essa inclusão.

Esse artigo teve como justificativa os desafios da inclusão dos autistas na Educação Regular na quais foram abordando os principias obstáculos para a inclusão dessas crianças e quais são os recursos oferecidos pela escola para atendê-los, levando em consideração a Lei ${ }^{\circ}$ 12.764, de 27 dezembro de 2012 que institui a Política Nacional de Proteção dos Diretos da Pessoa com Transtorno do Espectro Autista, que garante o acesso do autista em frequentar o ensino regular.

O objetivo desse estudo foi conhecer o Transtorno do Espectro Autista, suas características, também averiguação no âmbito escolar e convívio social oferecido pela escola. Contribuindo com informações e gerando conhecimento sobre o assunto, que está cada vez mais frequente no convívio escolar.

A metodologia da pesquisa está baseada em revisão teórica de artigos, tendo como principias teóricos, Mello, Rodrigues, Suplinos, Bereohff e outros, entrevistas, com profissionais da educação que falam sobre os obstáculos encontrados em desenvolver trabalhos pedagógicos e duas mães de crianças autistas que relatam as dificuldades encontradas ao matricular seus filhos na escola regular.

Ressalta-se que ao realizar pesquisas que envolvam pessoas, por meio de entrevistas, questionários deve ser submetidas a análise de um CEP - Comitê de Ética em Pesquisa com seres Humanos. E nós realizamos todos os tramites legais para que isso ocorresse.

Espera-se que esse artigo contribua para o conhecimento acadêmico, profissional, familiar e social, no que se refere aos avanços e possibilidades de melhorias em relação ao atendimento e tratamento das crianças com autismo no ambiente escolar.

\section{BREVE HISTÓRIA DO AUTISMO}

O termo autismo foi criado pelo psiquiatra Engene Bleuler tem origem grega: "autos" que significa "próprio" (ZAFEIRIOU et al., 2007), Clemens Benda (apud BENDER, 1959) destaca que o termo "idiotia", de origem grega tem o mesmo significado de "autismo".

Porém o primeiro a estudar sobre o autismo foi o médico psiquiatra e pediatra Leo Kanner chefe do John Hopkins Hospital nos Estados Unidos, no início de 1943 realizou uma pesquisa que nomeou 'distúrbio autístico do contato afetivo' que analisou onze crianças 
observando seu comportamento, Kanner observou as características do grupo, sendo que apresentavam comportamentos anormais de interação social, comunicação e estereotipados.

Kanner, em 1943, refere-se ao quadro com nome de Autismo Infantil Precoce, evidenciando sérias dificuldades de contatos com pessoas, ideias fixas em manter os objetos e suas situações sem variá-los, fisionomias inteligentes, alterações na linguagem do tipo inversão pronominal, neologismo e metáforas. (RODRIGUES, 2010, P.18).

Uma da teoria de destaque de Kanner é a "mãe geladeira" (PEARCE, 2006), que na sua concepção as crianças autistas não recebiam afetividade dos pais. Na qual sabemos que esse fator é irrelevante, pois não está relacionado diretamente aos pais o espectro do autismo, sendo que a criança pode nascer ou desenvolver no começo da infância as desordens do desenvolvimento neurológico.

Além dos estudos de Kanner teve outros pesquisadores como, Eugene Bleuler que descreve o sintoma relacionado à esquizofrenia, segundo (RODRIGUES, 2010 P.19), "Bleuler propõe uma ausência da realidade, com o mundo exterior, e consequentemente, impedimento ou impossibilidade de comunicar-se com o mundo externo, demostrando atos de um proceder muito reservado". Hans Asperger que escreveu um artigo "A psicopatia autista na infância", que dominou como empatia, incapacidade de interação social e movimentos descoordenados. Asperger também foi considerado como os demais importantes pesquisadores do autismo, e a Síndrome de Asperger levou o nome do estudioso.

O autismo é uma síndrome comportamental (e não um tipo de deficiência), com causas múltiplas. É um distúrbio de desenvolvimento que se caracteriza por déficit na interação social, expresso pela inabilidade em relacionar-se com o outro e usualmente combinado com dificuldades de linguagem e de comportamento. (APAE, 2011, P.8).

Apesar dos anos de dedicação dos pesquisadores, ainda não tem um diagnóstico preciso do que ocasiona o autismo, o que se pode afirmar é que afeta o neuro desenvolvimento, e é conhecido como Transtorno Global do Desenvolvimento não Especifica o autismo.

\subsection{CARACTERÍSTICAS DO AUTISMO}

As características do autismo por ser percebidas nos três primeiros anos de vida, ou seja, os pais devem estar atentos nas etapas do desenvolvimento da criança, segundo MELLO (2001, p.11) "o autismo é uma síndrome definida por alteração presente desde idades 
muito precoces, tipicamente antes de três anos idade, e que se caracteriza sempre por desvios qualitativos na comunicação, interação social e no uso da imaginação”.

A característica do autismo é classificada em três espectros sendo eles: a criança não desenvolve interação com outra pessoa; apresentada dificuldade na comunicação; e os que têm movimentos restritos e repetitivos. Esses espectros possuem graus de distúrbios que variam do leve ao grave podendo até apresentar mutilação em si mesmo.

Existem algumas classificações feitas por autores de acordo com as competências ou características intelectuais do autista como:

\footnotetext{
Alto funcionamento (ou Síndrome de Asperger) as pessoas são capazes de acompanhar o currículo de ensino comum, falar, desenvolver-se em uma profissão e cria vínculos afetivos;

Baixo funcionamento de deficiência intelectual, ausência de fala e de contato visual, sem demostrar interesse pelas pessoas ou pelos objetos. (APAE 2011, p. 8).
}

O transtorno do autismo é muito complexo ao ser falado, pois, possuem vários espectros que pode ser tratado de diferentes maneiras, há crianças que tem desenvolvimentos positivos apesar do diagnóstico e outros que "vivem no próprio mundo" parecem não notar as pessoas ao seu redor. FERREIRA, (2009, p.15) "nem todos são iguais e nem todos tem as mesmas características. Uns podem ser mais atentos, uns mais intelectuais e outros mais sociáveis, e assim por diante".

Em 2012 foi constituída a Lei 12.764 que institui a "Política Nacional de Proteção dos Direitos da Pessoa com Transtorno do Espectro Autista alterando assim o $3^{\circ}$ do art. 98 da Lei $\mathrm{n}^{\circ} 8.112$ de dezembro de 1990 (BRASIL, 2012)", e concede o direito aos alunos autistas de frequentarem o ensino regular, contribuindo assim com o seu desenvolvimento cognitivo e social.

A lei traz vários benefícios para que os autistas desfrutem de uma vida digna, com direito a participar da educação do ensino comum e terem acompanhantes especializados na sua trajetória escolar, segundo (BRASIL, 2012) "a pessoa com transtorno do espectro autista incluída na classe comum de ensino, terá direito ao acompanhante especializado. Garantindo que a pessoa com transtorno de espectro autista não seja submetida a tratamento desumano ou degradante e também não sendo privada de sua liberdade ou convívio familiar não sofrendo nenhuma discriminação de sua deficiência".

\subsection{O ÂMBITO ESCOLAR E SEUS DESAFIOS NA INCLUSÃO DO ALUNO AUTISTA.}


Atualmente com a sociedade em transformação há a luta pelos direitos humanos, e nas quais pessoas autistas estão sendo incluídas na instituição escolar, para tal é necessário que aconteça a mudança, no âmbito escolar e profissional. Era comum no Brasil a educação tradicional aode só frequentavam escolas os alunos "ditos como normais" pela sociedade, isso não existe mais, atualmente possuem leis que amparam a inclusão dessas pessoas na escola regular.

Com a evolução da sociedade a área da educação acabou não acompanhando o processo de renovação em se adaptar as necessidades e estão encontrando diversos desafios para fazer a inclusão dos alunos não só os autistas, mas todos os que possuem algum tipo de deficiência.

Começando pela estrutura física das escolas que devem estar adequadas com rampas de acesso, banheiros adaptados, sala de aulas organizadas e espaço para atividade ao ar livre.

$\mathrm{Na}$ educação inclusiva também e necessário que não aconteça o preconceito da equipe escolar, é fundamental a preparação dos profissionais que estarão envolvidos diretamente no convívio dessas crianças, pois todos contribuem para a inclusão do mesmo.

São vários desafios que precisam ser vencidos para que a inclusão aconteça, um deles é a quantidade de crianças por sala de aula, uma vez que a criança autista necessita de um espaço acolhedor que transmita tranquilidade para que a mesma possa se desenvolver, o fato de ter muitos alunos em um local pequeno faz com que o autista fique agitado interferindo negativamente no seu processo de aprendizagem. É necessário que a escola realize um trabalho de organização das turmas dividindo a quantidade de alunos por classe, para que assim possa ter domínio com todos os alunos inclusive o autista.

Um ponto crucial da educação inclusiva está na especialização dos professores, monitores e a falta de materiais pedagógicos acabam que os profissionais não têm orientação e capacitação profissional necessária para trabalhar com esses alunos, e também há a falta de materiais pedagógicos adaptados.

A falta de especialização adequada acaba recaindo sobre a área da educação, pois exige a capacitação dos profissionais, aonde também recaí um dos grandes desafios da inclusão que é falta de recursos financeiros que não é somente obrigação de uma das competências, mas dos fatores governamentais aonde a contribuição é precária, não sendo suficientes para investir na capacitação dos profissionais, os poucos que conseguem fazer um aperfeiçoamento na área é com recurso próprio, o que faz com que outros não possam ter essa oportunidade por que esses cursos são de alto custo.

Os desafios são muitos ainda há serem superados, e sempre terá alguma coisa para ser aperfeiçoado, o que não pode acontecer é a falta de interesse em solucionar os problemas, pois conforme mostra as pesquisas está havendo um aumento considerável de autismo, 
de acordo com as Nações Unidas do Brasil (07/04/2016) "Cerca de $1 \%$ da população mundial - ou um em cada 68 crianças - apresenta algum transtorno do espectro do autismo, e a ocorrência da condição neurológica tem aumentado. A maioria dos afetados são as crianças". O que significa que o número de crianças com Transtorno do Espectro Autista está aumentando e é necessário que a educação esteja preparada para realizar a inclusão dessas crianças para contribuir no seu desenvolvimento comportamental, cognitivo, interação social e estimulação da linguagem, pois não se pode excluí-las da sociedade e sim se adaptarem a elas, ou seja, os autistas são individuais não pode ser comparados, existem graus e evolução diferentes, uns poderão frequentar faculdades e se formarem em diferenças profissões, outro não, mais o importante é que todos tenham a mesma atenção. Segundo o Castoriadis citado por Valle $(1997$, p.) "O real é também, aquilo que pode ser transformado a utopia não estaria apenas em querer-se instalar a razão no imaginário, mais talvez mostrar que os dois, razão e imaginário são duas faces de uma mesma moeda".

Sabemos que há um longo caminho para percorrer, pois ainda encontramos resistências quanto a este assunto por termos poucas informações no contexto social e escolar, mas estamos em busca de transformação e aceitação das diferenças.

A intervenção pedagógica com o autista é de suma importância, pois é o começo da trajetória escolar e é nessa fase que os alunos aprendem a conviver com as diferenças se despindo de seus preconceitos. Na qual poderão compreender que a educação é para todos independente da deficiência e transtornos. Segundo a declaração de SALAMANCA (1994),

Toda criança tem direito fundamental à educação, e deve ser dada a oportunidade de atingir e manter o nível adequado de aprendizagem, aqueles com necessidades educacionais especiais devem ter acesso à escola regular, que deveria acomodá-los dentro de uma Pedagogia centrada na criança, capaz de satisfazer a tais necessidades, escolas regulares que possuam tal orientação inclusiva constituem os meios mais eficazes de combater atitudes discriminatórias criando-se comunidades acolhedoras, construindo uma sociedade inclusiva e alcançando educação para todos; além disso, tais escolas provêem uma educação /efetiva à maioria das crianças e aprimoram a eficiência e, em última instância, o custo da eficácia de todo o sistema educacional. (DECLARAÇÃO DE SALAMANCA, 1994, p. 1).

Evidentemente o professor encontrara desafios para realizar trabalhos pedagógicos com esse aluno, por apresentarem diferentes caraterística e estereotipias, pois o autismo não tem uma cartilha pronta que pode seguir e sim é necessário conquistar a confiança do aluno para depois estabelecer a metodologia de aprendizagem.

O autista tem dificuldade para assimilar muitas informações passada de uma só vez, um simples exemplo, "é para colorir um desenho, e depois guardar os lápis, pois corre o risco 
de perder ou quando a criança pede para ir ao banheiro utilizar expressões complexa como, vai num pé e volta no outro", ele poderá entrar em crise por não ter o domínio de como ira proceder, diferente de uma criança neuro típica que conseguirá acompanhar a informação corretamente. Segundo SUPLINOS (2009), "as ordens sendo claras facilita o entendimento da mesma, não provocando assim duplo sentido. Poucas palavras e expressões simples. Repetir a instrução com palavras diferenciadas também pode auxiliar o aluno a entender a ordem". São as simples ações que se tornam obstáculos, porem a intervenção do professor auxiliara a superar os desafios.

Como já há muito citado o transtorno do espectro autista possui várias características e estereotipias, tornando o seu aprendizado mais lento, porém possível, com a intervenção pedagógica dará a oportunidade de esta criança conviver com a diferença que fora da escola não terá, ou seja, quando o autista participa de atividades pedagógicas direcionadas a todos, ou adaptada para sua atender necessidade, o simples fato de ver a criança neuro típica fazendo a atividade já serve de motivação.

É importante estabelecer a rotina a ser seguida, que ofereça ao autista uma antecipação dos acontecimentos futuros, que possam dar tempo de se organizar evitando ou minimizando possíveis crises de ansiedade, segundo BEREOHFF (1995), "devemos entender a rotina com planejamento e organização". Como também é importante a estabelecer regras que todas as crianças terão que respeitar, isso inclui o autista, evidente que a comunicação para melhor entendimento é visual. Porém é comum o pensamento que crianças autistas não precisam seguir regras, mas ao contrário, é necessário ensinar que existem regras a serem cumpridas, pois a escola será uma ligação para a inclusão social que ajudara a criança compreender melhor o comportamento adequado.

\footnotetext{
Devem-se reforçar positivamente os comportamentos adequados e não se devem reforçar os comportamentos inadequados. Quando ocorrer um comportamento inadequado, deve-se ensinar o comportamento adequando que é esperado. Repete-se o ensino todas as vezes que sejam necessárias e controlase o ambiente para evitar que eventos do ambiente determinem, propiciem ou favoreçam a emissão de problemas de comportamento ou comportamento inadequados. (KHOURY, 2014 p.30)
}

A estimulação de comportamento não significa querer transformar o autista em pessoa neuro típica, e sim contribuir na organização de atitudes que são práticas no cotidiano, até então desconhecida pelo autista. De acordo (KHOURY, 2014). "O ensino do comportamento de solicitação é importante para a criança aprender quais são os comportamentos aquedados para pedir o que precisam".

A contribuição do professor capacitado ajuda a conquistar a independência dessas crianças, que podem se desenvolver desde o comportamento, organização, interação 
social, linguagem até no caso do autista não verbal que também precisa desse apoio profissional.

\title{
1.3 MÉTODOS: TEACCH E ABA
}

O método TEACCH foi criado em 1964 por Eric Schopler, segundo (FERREIRA,2016) "Schopler e colaboradores desenvolveram no Departamento de Psiquiatria da Faculdade de Medicina da Carolina do Norte nos Estados Unidos um método em apoio aos pais de crianças autistas que reclamavam da falta de atendimento educacional".

TEACCH é uma terapia podendo ser utilizada por profissionais da área médica e pedagógica, tem como objetivo auxiliar no desenvolvimento de comunicação visual, verbal e não verbal das crianças autistas. Atuando também na preparação do ambiente escolar, oferecendo local de aconchego e segurança para assim desenvolver os trabalhos pedagógicos.

\begin{abstract}
O método TEACCH utiliza uma avaliação denominada PEP-R (Perfil Psicoeducacional Revisado) para avaliar as crianças e determinar seus pontos fortes e de maior interesse, e suas dificuldades, e a partir desses pontos, montar um programa individualizado. O TEACCH se baseia na adaptação do ambiente para facilitar a compreensão da criança em relação a seu local de trabalho e ao que se espera dele. Por meio da organização do ambiente e das tarefas de cada aluno. TEACCH visa desenvolvimento da independência do aluno da forma que ele precise do professor para o aprendizado de atividades novas, mas possibilitando-lhe ocupar grande parte de seu tempo de forma independente. (MONTE, 2004 p.9)
\end{abstract}

É importante que as crianças autistas recebam atenção individual em relação ao seu espectro, ou seja, entender quais seus pontos positivos e negativos que precisam ser trabalhados. Após essa avaliação é fundamental que a escola ofereça um período de adaptação para a criança se familiarizar com o ambiente que foi inserido. A participação da família é de grande aproveito, pois eles poderão contribuir com a escola organizando uma rotina diária onde os responsáveis podem auxiliar as tarefas pedagógicas e estimulando a criança.

Outro método que contribui para a aprendizagem do autista é a ABA Análise Comportamental Aplicado, de acordo com (MELLO, 2001) "o método ABA é um tratamento comportamental indutivo, ou seja, constroem por etapas com a criança novas habilidades ainda não trabalhadas. Assim, as habilidades são construídas individualmente, de forma integrada a uma indicação ou instrução". 
A Análise Comportamento Aplicado é um método que pode ser aplicado em todas as pessoas para avaliar o seu comportamento, não só especificamente o autista. Mais a ABA ganhou destaque na estimulação do autismo por que é possível estabelecer atividades que contribui no seu desenvolvimento de aprendizagem, ou seja, vai ampliar o reportório da comunicação, interação social e o estereotipado.

O método ABA poderá ser aplicado por profissionais terapêuticos educacionais, professores e pais que fizeram o curso capacitatório de análise do comportamento.

\section{DESENVOLVIMENTO}

A base desta pesquisa foi realizada na Escola Municipal Mauro Fascincani, no município de Angélica/MS, na qual os colaboradores estão em constante evolução para melhor atender as multiplicidades dos alunos. As entrevistas foram realizadas com diálogos sobre a temática para interagir e criar vínculos com os participantes em seguidas foram realizadas as respostas dos questionários e anotações.

Os participantes terão seus nomes mantidos sob sigilo, mas para melhor compreensão do estudo vamos referir-se a equipe pedagógica como; coordenadora pedagógica CP1, professora P2, professora P3 e incluímos a colaboração das mães das crianças autistas MG1, MH2, MK3.

Tabela1 de formação acadêmica:

\begin{tabular}{|c|c|c|c|}
\hline Profissionais & $\begin{array}{l}\text { Conclusão do } \\
\text { Curso }\end{array}$ & $\begin{array}{l}\text { Graduaçãa e Pós } \\
\text { Graduação }\end{array}$ & $\begin{array}{ll}\text { Anos de } \\
\text { Experiência }\end{array}$ \\
\hline $\mathrm{CP} 1$ & 2004 & $\begin{array}{l}\text { Pedagogia com } \\
\text { Pós-graduação em } \\
\text { Psicopedagogia }\end{array}$ & $\begin{array}{l}06 \text { anos de docência } \\
\text { e } 10 \text { anos de } \\
\text { coordenadora } \\
\text { pedagógica. }\end{array}$ \\
\hline $\mathrm{P} 2$ & 2001 & $\begin{array}{lr}\text { Pedagogia } & \text { com } \\
\text { Pós-graduação em } \\
\text { Psicopedagogia } \\
\text { Libras }\end{array}$ & $\begin{array}{l}19 \text { anos de } \\
\text { docência. }\end{array}$ \\
\hline P3 & 2013 & $\begin{array}{lr}\text { Licenciatura } & \mathrm{em} \\
\text { Pedagogia } & \text { com } \\
\text { Pós-graduação } & \text { em } \\
\text { Alfabetização } & \mathrm{e} \\
\text { Letramento } & \\
\end{array}$ & $\begin{array}{l}07 \text { anos } \\
\text { docência. }\end{array}$ \\
\hline
\end{tabular}


Tabela 2 mães participantes e perfil dos filhos:

\begin{tabular}{|l|l|l|}
\hline Mãe & Idades & Autismo \\
\hline MG1 gêmeos & 08 anos & Asperger \\
\hline MH2 & 11 anos & Não verbal \\
\hline MK3 & 14 anos & Severo \\
\hline
\end{tabular}

A instituição citada na elaboração desta pesquisa, não dispunha de alunos autistas matriculados, mas colaborou com o estudo para expor os principais obstáculos encontrados no trabalhar da inclusão. É importante destacar que os resultados desta pesquisa não é denegrir a instituição ou os entrevistados, mas diagnosticar as falhas ocorrentes na educação inclusiva.

Ao indagar a equipe pedagógica sobre a inclusão das crianças autistas e de outras deficiências no ensino regular, todos estão de acordo, porém ainda falta adaptação da estrutura escolar e apoio na capacitação dos profissionais, ou seja, precisam tomar consciência que a diferença existe, é importante que todos do conjunto escolar e familiar estejam preparados para contribuir no desenvolvimento e aprendizado desses alunos.

CP1: "Verdadeiramente não possuímos as estruturas e materiais lúdicos necessários para o trabalho pedagógico, também há necessidade de uma formação mais profunda dos profissionais no assunto, pois os professores possuem especializações, mas necessitam de mais aprofundamentos. Ainda que o aluno com transtorno autista seja matriculado e frequente a escola regular, esse fato, por si só, não garante o seu desenvolvimento. É essencial que toda a comunidade escolar esteja envolvida no processo de inclusão, que o tema seja amplamente debatido e que todos assumam as suas responsabilidades, não somente o professor dentro da sala de aula".

É indiscutível a falta de investimento financeiro para a capacitação dos profissionais que trabalham diretamente e indiretamente com autistas, assim como a falta de materiais pedagógicos, ou seja, se houvesse o financiamento, a educação teria condições de se preparar para receber os alunos tendo um apoio maior para desenvolver as atividades pedagógicas. Para contribuir na relação social a realização de palestras de conscientização sobre o autismo e outras deficiências seria fundamental, pois faria a ponte de ligação entre instituição de ensino e as famílias dessas crianças que necessitam desse apoio.

CP1: A falta de investimentos e preparo do professor é uma das principais dificuldades, pois existem as políticas públicas para a inclusão, mas o investimento é mínimo e o professor tem que 
investir na sua formação e conhecimentos por conta própria para encarar o desafio. Outro desafio é a questão da interação desse aluno com as outras crianças, uma vez que as pessoas com autismo apresentam muitas dificuldades de socialização, sabemos que são inúmeros os benefícios da interação entre crianças e adolescentes, com deficiências ou não, que compartilham do mesmo espaço físico e de um processo pedagógico que propicia a troca e a cooperação. $O$ apoio do professor é fundamental para que esse aluno participe de forma produtiva.

As professoras ao serem indagadas sobre a dificuldades em trabalhar com o autista em sala de aula, com experiência anterior a professora $\mathrm{P} 2$, ressaltam existem vários fatores que contribuem na inclusão desse aluno, um dos desafios são as metodologias devem aplicada de forma que desperte o interesse do aluno, e sabemos que cada aluno requer metodologia especifica para seu aprendizado, o autista exige mais dedicação pois seus níveis de complexidades em compreensões são maiores, o que é necessário ter atendimento personalizado do indivíduo e o mais importante acreditar no seu desenvolvimento.

Ter leis que amparam a inclusão dos autistas e crianças especiais, não significam que os todos professores já estão capacitados e ambientes escolares adequados, ainda a falta de capacitação do professor, pois nas pequenas cidades não tem recursos financeiros destinados esse área e o profissional tem que arcar com as despesas de cursos por conta própria, sem falar âmbito escolar que não estão adaptados a super lotação das salas de aulas, também o apoio familiar tornando mais difícil a inclusão.

P2: "Já tive há algum tempo um aluno autista na sala do $2^{\circ}$ ano, o maior desafio é o entendimento de todos os profissionais da educação pelo nível cognitivo desse aluno, seus gostos, seus comportamentos, somente depois disso é possível que o professor busque a metodologia que torne o aprendizado desse aluno mais atrativo e eficaz, todo esse processo só é possível com capacitação e muita leitura da parte do professor, fato este que infelizmente não acontece; e não há incentivo para que professores possam se capacitar na área da inclusão." P3: "O professor está muito despreparado para lidar com essa questão. Atualmente o sistema educacional mais exclui do que inclui. Fala-se tanto em inclusão mas não preparam o professor nem a equipe pedagógica para lidar com esses desafios. Salas super lotadas, e na maioria das vezes sem o menor apoio da secretaria educacional e dos pais. Querem que o professor sem preparo dê conta de educar e ensinar sem um apoio, um suporte. Faz-se 
necessário capacitar esses profissionais da educação constantemente".

Em contraposição estão os pais desses alunos esforçando-se para conquistar espaço na educação regular, querendo que seus filhos tenham os mesmos direitos que outras crianças, pois é fundamental a intervenção precoce no desenvolvimento cognitivo e social. Mas esses alunos ainda não desfrutam dos seus direitos, uma vez as instituições não disponibilizaram estruturas adequadas para atendê-los.

MG1: "A dificuldade vai desde a permanência do autista sentado na sala de aula até os barulhos das crianças, pois o autista tem dificuldade sensorial, tem vontade de se movimentar como também o barulho do ambiente escolar e das próprias crianças lhe tiram a concentração e desvia a atenção. $O$ relacionamento social que por dificuldade de iniciar a interação, percebe a diferença e muitos por fim se isolam a dificuldade com o novo e mudança, pois todos os dias têm conteúdos novos a serem estudados e a escola regular não respeita o tempo de aprendizado desta criança não levando em consideração suas dificuldades”. MH2: "Tentei fazer a inclusão mais não foi possível, pois, meu filho que não é verbal, nem alfabetizado, eu vejo dificuldade no barulho, gritos e muita conversação ao mesmo tempo, e a quantidade de alunos em sala de aula, dificultando assim o aprendizado, e desencadeando muitas estereotipias e futuras crises".

Infelizmente a escola não sabe o que fazer quando chega um aluno autista para ser incluído, ficam sem ação, os professores adaptam no seu modo as atividades para trabalhar com esse aluno que acabem tendo dificuldades em compreender o que está sendo proposto, ou seja, está no ensino regular, porém não tem aproveitamento de qualidade, em contra partida as mães se veem impotentes, pois, desejam o progresso de seus filhos no ensino regular, mas falta apoio da escola, "que oferece essa inclusão e acabam excluindo", pois a lei determina que sejam garantidas as vagas dessas crianças favorecendo a inclusão, mas o que realmente acontece é a exclusão por falta de estrutura escolar e profissionais capacitados.

MG1: "Encontramos todas as dificuldades possíveis, pois, os professores não são qualificados para lidarem com a inclusão, $e$ os alunos inseridos na sala de aula, sem nenhum respaldo para evoluírem cognitivamente, ficam na maioria das vezes largados e esquecidos, não entendem alguns conteúdos propostos. E fica bem difícil, pois, meus filhos são autista leve (Asperges), mais mesmo assim se negam a fazer lições, querem alguém do lado ajudando por terem falta de segurança na hora de fazer as 
atividades, teria que ter uma auxiliar para ajudar, mais infelizmente a Lei ainda não está sendo praticada. Espero que num futuro próximo tenha consciência que a inclusão é boa para todos, e as leis realmente funcionem". MK3 “A legislação não é tão fácil de ser aplicada. Pois tudo que depende de recursos financeiros, como por exemplo, a contratação de uma monitora, exige tempo, desgaste psicológico e muita luta com o sistema. A escola é obrigada a incluir, porém nem sempre aceita de bom coração. Apesar de aceitem o meu filho na escola regular sempre senti resistência nas reuniões, como até mesmo aconselhamento para procurar algo mais preparado".

É possível pactuar que tanto a instituição com as mães pontua os mesmos motivos que precisam ser analisados com mais cuidado, pois não podemos afirmar que todas as instituições pactuam com as mesmas dificuldades, mas podem ter fragmentos que podem ser iguais. Podemos sugerir que a maior resistência do sucesso da Educação Inclusiva seja a dificuldades dos professores em se especializar por conta própria que acaba se tornando uma frustração quando não recebem o apoio e o reconhecimento que lhe é direito.

Todos dos fatores acima apresentados apontam a necessidade de uma transformação, que mudanças sejam feitas em todos os setores da educação, sendo assim as mães verão seus desejos realizados um futuro próximo, onde as novas crianças autistas ou com outras deficiências possam desfrutar das evoluções que essas mães estão em busca, pois às vezes lutamos por algo que poderá ter resultados em longo prazo.

MG1: "Eu espero que num futuro próximo possamos colocar realmente a lei de inclusão para funcionar e não ser só no papel, precisamos de professores preparados, números de turma reduzida quando tiver uma criança especial em sala, matérias adaptadas de acordo com que a criança consegue fazer sem gerar estresse e uma possível agressividade, mais aulas dinâmicas e tecnológicas, mais esportes, pois isso gera sensação de bem estar, aumentando a auto-estima e consequentemente menos hiperatividade. Que o modelo de ensino seja reformulado para além da sala de aula, com aulas mais práticas e visuais para que todos possam aprender e que fossem respeitados os limites de cada criança, e que a escola também observe nas crianças seus potenciais, pois, eles são muito capazes." MG2: "Na minha opinião teria que reeducar a escola inteira, desde o guarda até o diretor, para que no futuro possam reconhecer as dificuldades de um autista, que sabendo, conversar, estimular ele será um autista capaz como pessoas neuro típica. A escola precisa de organização desde a sala de aula, alunos e os professores, assim 
o autista se encontrará". MK3: "Espero que no futuro a escola seja preparada e capacitada para receber uma criança autista, não tendo uma cartilha pronta, mas tendo conhecimento do que é e como reagir as suas estereotipias e outros".

Ainda é comum não observarmos a diferença quando está inserida em outra família, que não seja a nossa, mas para podermos evoluir devemos respeitar a todos independentemente qual seja sua deficiência ou transtorno, principalmente na área da educação, pois ela faz que haja a interação social para a formação de uma nova sociedade libertadora de paradigmas. Segundo Paulon; Freitas; Pinho (2005, p. 25-26), "As escolas, de modo geral, têm conhecimento da existência das leis acerca da inclusão de pessoas com necessidades educacionais especiais no ambiente escolar e da obrigatoriedade da garantia de vaga para estas. As equipes diretivas respeitam e garantem a entrada destes alunos, mostrando-se favoráveis à política de inclusão, mas apontam alguns entraves pelo fato de não haver a sustentação necessária, como por exemplo, a ausência de definições mais estruturais acerca da educação especial e dos suportes necessários à sua implementação".

\section{CONSIDERAÇÕES FINAIS}

Colocam-se muitas dificuldades para incluir o aluno autista no ensino regular, mesmo sendo um direito adquirido por lei, ainda há o preconceito ao dizer que o autista não possui a capacidade de se desenvolver em uma escola regular, o que resulta na exclusão desse aluno. É importante ressaltar que frequentar a escola é direito de todas as crianças, independente se há deficiência ou não, é fundamental as escolas trabalharem com a educação inclusiva, uma vez que assim há possibilidade de dar oportunidade para todas as crianças a terem acesso à educação através do ensino regular.

A inclusão das crianças autistas no ensino regular é um assunto delicado, pois ainda possuem muitos obstáculos a serem vencidos. Então é comum as escolas recusarem os alunos por não terem recursos financeiros para estruturar as salas de aulas e obterem os materiais lúdicos necessários (livros, jogos, comunicação alternativa). Também a maioria das escolas não oferece suporte para os profissionais buscarem a capacitação profissional para atenderem tal demanda e por último as escolas não possuem o chamado projeto de inclusão, que traz em seu conteúdo a apresentação do convívio escolar onde se trabalham as atividades pedagógicas que irão contribuir para o desenvolvimento cognitivo e socialização, essa interação traz aprendizado para todos, pois ensina a tolerância e o respeito às diferenças. Esses conjuntos de fatores fazem com que as escolas não se sintam capazes em receberem tais alunos, fazendo assim a exclusão dos mesmos. 


\section{REFERENCIAS}

FERREIRA, Patrícia Palmerino Terra. A Inclusão da Estrutura TEACCH na Educação Básica. $\quad$ Disponível em https://www.aacademica.org/editora.prospectiva.oficial/24.pdf Acesso em 22/08/2020.

AMBRÓS. Danieli Martins. O aluno com transtorno do espectro autista na sala de aula: caracterização, legislação e inclusão. Disponível em <ebooks.pucrs.br/edipucrs/anais/i-seminario-luso-brasileiro-de.../completo-3.pdf>. Acesso em 24/08/2020.

BARBOSA, Amanda Magalhães. (2013). ZACARIAS, Jaqueline da Cruz (2013) MEDEIROS, Kesia Natália (2013). NOGUEIRA, Ruth Kesia Silva (2013). O Papel do Professor Frente à Inclusão de Crianças com Autista. Disponível em <http://www.revistas.udesc.br/index.php/arteinclusao/article/view/11641>. Acesso em 06/08/2020.

BRASIL. Lei Brasileira de Proteção aos Autistas. Disponível em, <www.planalto.gov.br/ccivil_03/_ato2011-2014/2012/lei/112764.htm>. Acesso em 06/08/2020.

ORRÚ. Sílvia Ester. Fundação de Encino Octavio Bastos, Brasil. A Formação de Professores e a Educação de Autistas. Disponível em, <https://rieoei.org/historico/deloslectores/391Orru.pdf 08/08/2018> Às 21:00>. Acesso em 08/08/2020.

TULIO, Adriana Girelli e CASTANHA, André Paulo. Os desafios da escola pública paranaense na perspectiva do professor PDE2013. Disponível em <http://www.diaadiaeducacao.pr.gov.br/portals/cadernospde/pdebusca/producoes_pde/2 013/2013_unioeste_edespecial_artigo_adriana_girelli_tulio.pdf Acesso em: 24/08/2020

SIQUEIRA Márcia e GUEDES Ivan Claudio A Intervenção Psicopedagogia para Inclusão de uma Criança Autista na Educação Infantil. Revista Acadêmica Faculdade $\begin{array}{llllll}\text { Progresso } & \text { V. } & 4 & \text { N.1, } & 2018 & \text { Disponível }\end{array}$ <https://www.google.com/search?q=Revista+Acad\%C3\%AAmica+Faculdade+Progress $\mathrm{o}+\mathrm{V} .+4 \% 2 \mathrm{C}+\mathrm{N} .1 \% 2 \mathrm{C}+2018+\mathrm{A}+$ Interven $\% \mathrm{C} 3 \% \mathrm{~A} 7 \% \mathrm{C} 3 \% \mathrm{~A} 3 \mathrm{o}+$ Psicopedagogia + para + Inclus \%C3\%A3o+de+uma+Crian\%C3\%A7a+Autista+na+Educa\%C3\%A7\%C3\%A3o+ Infantil.\&oq=Revista+Acad $\% \mathrm{C} 3 \% \mathrm{AAmica}+$ Faculdade+Progresso+V.+4\%2C+N.1\%2C $+2018+\mathrm{A}+$ Interven $\% \mathrm{C} 3 \% \mathrm{~A} 7 \% \mathrm{C} 3 \% \mathrm{~A} 3 \mathrm{o}+\mathrm{Psicopedagogia}+$ para+Inclus\%C3\%A3o+de+ uma+Crian\%C3\%A7a+Autista+na+Educa\%C3\%A7\%C3\%A3o+Infantil.\&aqs=chrome. .69i57.1212j0j7\&sourceid=chrome\&ie $=U T F-8>$ Acesso em 23/08/2020. 
SUPLINO. Profa. Dra. Maryse. Inclusão Escolar de Alunos com Autismo. Disponível em < http://files.inclusaoescolar.webnode.com.br/200000010-8d32a8e2d2/Inclusao-dealunoscom-autismo.pdf $>$. Acesso em 08/08/2020. 